\title{
Concerning the vitamin $D$ reference range: pre-analytical and analytical variability of vitamin D measurement
}

\author{
Davide Ferrari ${ }^{1}$, Giovanni Lombardi², Giuseppe Banfi',3 \\ ${ }^{1}$ Department of Biosciences, University of Parma, Parma, Italy. \\ ${ }^{2}$ Laboratory of Experimental Biochemistry and Molecular Biology, IRCCS Istituto Ortopedico Galeazzi, Milano, Italy \\ ${ }^{3}$ Vita-Salute San Raffaele University, Milano, Italy \\ *Corresponding author: giovanni.lombardi@grupposandonato.it
}

\begin{abstract}
Unlike other vitamins, the vitamin D concentration in blood varies cyclically over the course of the year in relation to genetic (gender, ethnicity, polymorphisms) and environmental factors (sunlight exposure, diet, food-related or direct vitamin D supplementation, skin pigmentation). Although the major diagnostics manufacturers have recently developed improved automated 25-hydroxy vitamin D immunoassays, the intra- and interlaboratory variability is still high (especially at low vitamin D concentrations) which might lead to incorrect vitamin D deficiency/insufficiency diagnosis. Moreover, despite recent efforts to standardize the assay and minimize its variability, the current bias for measured vitamin $D$ concentrations is often still above the desirable $\pm 10 \%$ criterion. Because the implications of low vitamin $D$ concentrations in non-skeletal diseases are still partially unknown, international guideline recommendations for establishing meaningful ranges, at any time over the course of the year, irrespective not only of environmental and personal factors but also of instrumental variability, are needed. In this review, we discuss the main factors that influence the variability of vitamin $D$ concentrations and whether a centile curve, individually calculated by a theoretical equation considering such factors, might be better suited than a fixed limit to assess abnormal vitamin $D$ concentrations in otherwise healthy subjects. Vitamin $D$ reference ranges during pregnancy, childhood, or diagnosed illnesses, which merit separate discussion, are beyond the scope of this review.
\end{abstract}

Key words: vitamin D; biological variability; analytical variability; standardization; DEQAS

\section{Introduction}

The term vitamin D refers to a group of related steroid hormones involved in several physiological processes centred on the maintenance of calcium homeostasis, but also of phosphate, iron, and zinc, through its binding to the vitamin D receptor (VDR) (1). After binding the high-affinity vitamin D metabolite 1,25-dihydroxyvitamin, the receptor undergoes homodimerization and heterodimerization to a retinoic acid $X$ receptor (RXR) (2). These complexes recognize specific DNA sequences that regulate the transcription of genes encoding proteins that mediate calcium and skeletal metabolism: osteocalcin, osteopontin (SPP1) and bone sialoprotein (BSP) are involved in the mineralization of the bony extracel- lular matrix (ECM); membrane calcium channel TRPV6 is involved in intestinal calcium absorption; parathyroid hormone (PTH) and the PTH-related protein (PTHrp) are involved in calcium homeostasis and vitamin $D$ activation; receptor antagonist of nuclear factor kappa-B ligand (RANKL) is involved in osteoblast-osteoclast cross-talk in bone as well as in the immune regulation of osteoclastogenesis; lowdensity lipoprotein receptor-related protein 5 (LRP5) is involved in Wnt signalling in bone and in other Wnt-dependent tissues; cystathionine- $\beta$ synthase (CBS) catalyses the first step of transsulfuration of L-homocysteine in L-cystathionine; as well as many others (3-5). Vitamin D also increases intes- 
tinal calcium absorption by inducing the expression of calbindin, a calcium-binding protein that participates in calcium transport across the cell (2). Vitamin $D$ is also involved in the homeostasis of other ions like iron, manganese and zinc by regulating the expression of the SLC39A2 gene which plays an important role in iron homeostasis and the SLC30A10 gene which encodes the metal transporter ZnT10 (6-8).

There are two forms of vitamin D: vitamin D3 and vitamin D2 (Figure 1). Upon cutaneous exposure to ultraviolet B (UVB) radiation, cholecalciferol (vitamin D3) is synthesized from the photochemical ring-opening and subsequent thermal isomerization of the precursor 7-dehydrocholesterol (provitamin D) by endogenous synthesis (9). Vitamin D3 is hydroxylated to form 25-hydroxy vitamin D3 $(25(\mathrm{OH}) \mathrm{D}$, calcidiol), the major circulating human vitamin $\mathrm{D}$ metabolite, which is then catalysed in the liver by the enzyme 25-hydroxylase (CYP2R1) (10). Further hydroxylation activated by the enzyme 1-a-hydrolase occurs in the kidney to produce the biologic active form 1,25-dihydroxyvitamin D3 (1,25(OH) 2 D3, calcitriol) (10). Vitamin D2 (ergocalciferol), which accounts for a smaller amount, is of exogenous origin and derives from dietary sources such as plants or fish. Like vitamin D3, vitamin D2 is metabolized in the liver and the kidneys to form 1,25-dihydroxyvitamin D2 $\left(1,25(\mathrm{OH})_{2} \mathrm{D} 2\right)$ $(10,11)$. The abundance of $25(\mathrm{OH}) \mathrm{D}$ and $1,25(\mathrm{OH})_{2} \mathrm{D}$ is enzymatically regulated by the enzyme CYP24A1 which, by adding a hydroxyl group in position 24, lowers the concentrations of both metabolites (12). Vitamin D deficiency can cause rickets in infants and osteomalacia in adults, increasing the risk of osteoporotic fractures (13). Since UVB radiation is necessary to synthesize cholecalciferol, vitamin $D$ deficiency in populations living at high latitudes is common especially in winter. However, vitamin $\mathrm{D}$ deficiency has become increasingly common also among populations living at lower latitudes owing to the changes brought about by the adoption of modern lifestyle habits (e.g., less outdoor activity, greater usage of sunscreens) often associated with not meeting daily UVB requirements (14-16). Physical activity seems to be another important factor in the determination of vitamin $D$

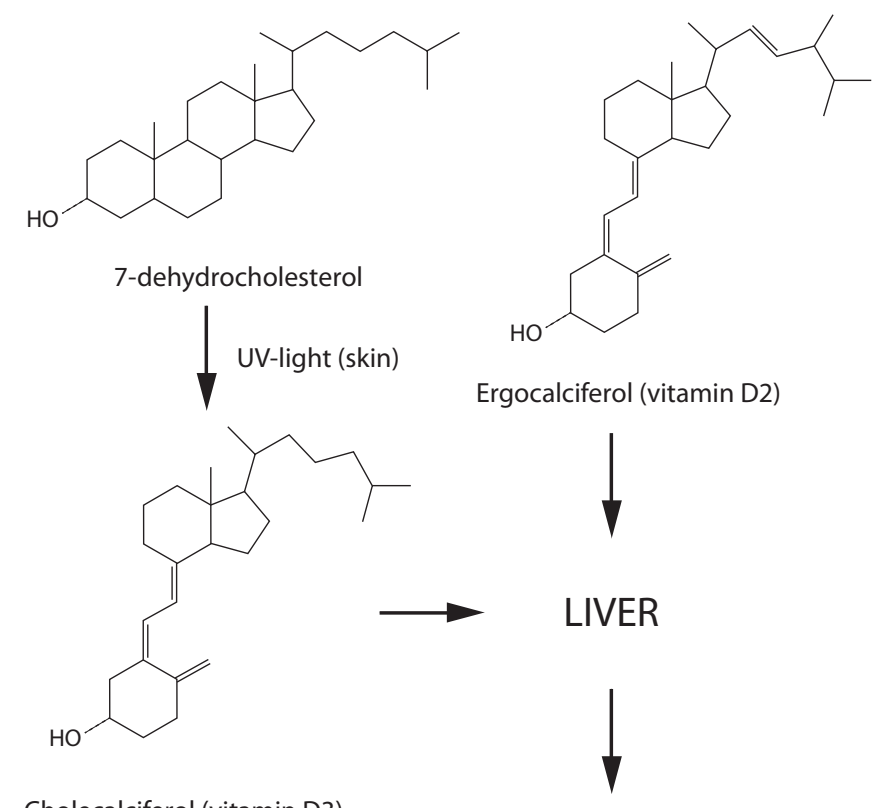

Cholecalciferol (vitamin D3)

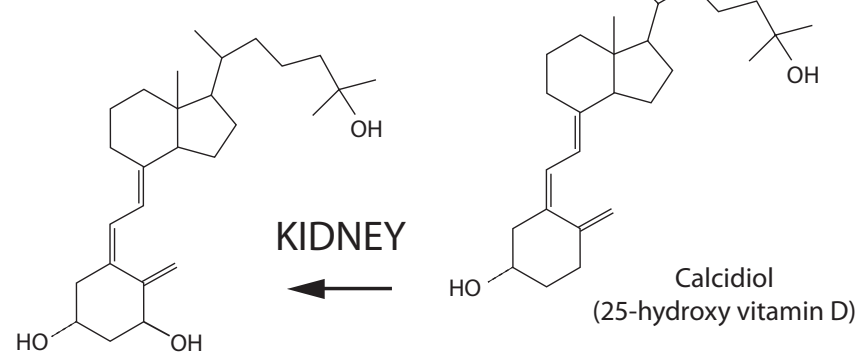

Calcitriol (1,25-dihydroxycholecalciferol or 1,25-dihydroxy vitamin D)

FIGURE 1. Vitamin D synthesis.

7-dehydrocholesterol (provitamin D) photoreacts in the skin to produce cholecalciferol (vitamin D3). Ergocalciferol (introduced with diet) and cholecalciferol are transformed in calcidiol, by the enzymes present in the liver. The final hydroxylation step exerted by the enzyme CYP27B1, to produce the active form of vitamin $\mathrm{D}$ (calcitriol), occurs primarily in the kidney.

concentrations, as documented by the surprisingly high prevalence of vitamin D insufficiency, and even deficiency, in professional athletes regardless of amounts of the sunlight exposure during indoor or outdoor activities (17-19). Because vitamin D plays a vital role in bone health, inflammation and immunity, skeletal muscle contraction, neuromuscular communication, and cardiovascular function, it is plausible that a suboptimal vitamin $D$ status increases the risk of muscular overuse-related symp- 
toms and inflammatory disease (20). Other factors that may impair the synthesis of active D-metabolites $\left(25-(\mathrm{OH}) \mathrm{D}, 1,25-(\mathrm{OH})_{2} \mathrm{D}\right.$ and $\left.24,25-(\mathrm{OH})_{2} \mathrm{D}\right)$ in athletes include skin pigmentation, early- or lateday training, indoor training, geographic location, and extensive sunscreen usage (17).

At present, serum total $25(\mathrm{OH}) \mathrm{D}$ is considered the best biomarker for assessing vitamin D status (21). It is measured by summing the 25-hydroxylated form of the exogenous D2 and the endogenous D3, also called 25(OH)D2 and 25(OH)D3, respectively, both of which have the same biological importance. Although $25(\mathrm{OH}) \mathrm{D}$ is not the active metabolite, it is characterized by a longer circulating half-life than 1,25-(OH) 2 and it is not dependent on PTH which, instead, controls the enzymatic hydroxylation at $\mathrm{C} 1$ (17). From an analytical point of view, 25(OH)D2 and 25(OH)D3 can be discriminated by chromatographic techniques or mass spectrometry, whereas full or partial cross-reactivity is observed when using immunoassay-based methods. Importantly, unless a patient is taking vitamin D supplementation, 25(OH)D2 usually accounts for less than $5 \%$ of total $25(\mathrm{OH}) \mathrm{D}(22,23)$. Based on international measurement standards, serum total $25(\mathrm{OH}) \mathrm{D}$ concentration must be reported in nanomoles per liter ( $\mathrm{nmol} / \mathrm{L})$; however, the use of the unit nanograms per milliliter $(\mathrm{ng} / \mathrm{mL})$ is very common, especially in the United States. A 2.6 multiplication factor can be used to convert $\mathrm{ng} / \mathrm{mL}$ into $\mathrm{nmol} / \mathrm{L}$ (24).

In the bloodstream, most $25(\mathrm{OH}) \mathrm{D}$ is bound to vitamin $\mathrm{D}$ binding proteins (VDBP) and only a small amount circulates in its free active form and, hence, is able to bind to the VDR (25). Since so many environmental and genetic factors can influence vitamin $D$ synthesis, defining a reliable desirable range remains challenging. Furthermore, because of its hydrophobic nature, its high affinity for VDBP, and analytical difficulties, which will be discussed below, 25(OH)D has been defined as a "difficult analyte" (26-28). Accordingly, the number of publications on how to measure vitamin $D$ has increased in the past decade. To date, only Australia uses a reference range that takes seasonal variation into account (29). There is no agreement on the normal ranges for serum total $25(\mathrm{OH}) \mathrm{D}$ : the
U.S. Institute of Medicine (IOM) suggested a minimal concentration of $52 \mathrm{nmol} / \mathrm{L}$, while the Endocrine Society (ES) suggested a minimal concentration $78 \mathrm{nmol} / \mathrm{L}(13,30,31)$. Having such diverse cutoff levels will obviously affect patient categorization.

In this review we discuss the environmental, genetic, and instrumental factors that may influence the measured concentrations of total $25(\mathrm{OH}) \mathrm{D}$ and whether a variable range might be more suited than a fixed limit to asses abnormal vitamin D concentrations.

\section{Pre-analytical variability}

\section{Seasonal effect}

Because of its biosynthetic pathway, vitamin D concentration is highly dependent on UVB radiation dose (Figure 1) and varies seasonally at latitudes distant from the equator (32). In general, the maximum amount of total serum $25(\mathrm{OH}) \mathrm{D}$ in populations living in the northern hemisphere is higher in summer and autumn and lower in winter and spring (16,33-35). O'Neil et al. showed that the "vitamin D winter", defined as the time of year when UVB doses are insufficient to promote vitamin $D$ synthesis, lasts for up to 8 months at latitudes between 60 and $70^{\circ} \mathrm{N}, 5$ to 6 months at latitudes between 51 and $59^{\circ} \mathrm{N}$, and 2 months or does not occur at all at latitudes between 35 and $40^{\circ} \mathrm{N}$ (33). Krzywanski et al. published interesting data about the $25(\mathrm{OH}) \mathrm{D}$ concentration in a group of Polish athletes divided into two groups according to whether they were engaged in outdoor sports (OUTD) or indoor sports (IND) (16). Additional subgroups were created by dividing the athletes who trained during winter months in countries at lower latitudes like South Africa or Tenerife (SUN) and those who, having inadequate vitamin D status $(<$ $78 \mathrm{nmol} / \mathrm{L}$ ), were supplemented orally (SUPL). The results showed that the mean value during the course of the year in the IND group was always below the $78 \mathrm{nmol} / \mathrm{L}$ (minimal concentration suggested by the ES), whereas the OUT group had mean concentrations of $94 \pm 3 \mathrm{nmol} / \mathrm{L}$, slightly above the minimal concentration, but only in the summer. Furthermore, during the winter, both the SUN and 
the SUPL group had higher 25(OH)D than the OUT group by $85 \%(\sim 120 \mathrm{nmol} / \mathrm{L})$ and $45 \%(\sim 100$ $\mathrm{nmol} / \mathrm{L})$, respectively, bringing their vitamin $D$ concentrations above the minimal concentration (16). Comparably, we have recently demonstrated that the prevalence of vitamin D insufficiency is high in Italian soccer players, despite the latitude, and that $25(\mathrm{OH}) \mathrm{D}$ concentrations follow the classical circannual rhythm regardless of the effort spent (36).

Latitude-related lower UVB availability does not always correspond to an increased prevalence of vitamin $D$ deficiency, as shown in the study by O'Neill et al. (33). Among adults living in northern European countries like Iceland and Norway, there were fewer cases (2 - 9\%) of vitamin D deficiency in winter as compared to their counterparts living in middle European countries like Ireland (23\%). The probable reason is dietary habits: in Norway and Iceland the traditional diet includes large use of fatty fish and cod liver oil and consumption of other vitamin $D$ supplements is more common $(37,38)$. At lower latitudes, in contrast to the recommendations recently published by the European Food Safety Authority (EFSA) on dietary reference values for vitamin $D$, supplementation is still uncommon (39). This hypothesis is further substantiated by the fact that Norwegian adolescents (aged 13 years), who follow less traditional dietary habits, had, on average, a vitamin D concentrations 26 $\mathrm{nmol} / \mathrm{L}$ lower than adults (33). Even more surprisingly were the results by Katrinaki et al. obtained on the population of Crete. Although the UVB availability allows for basically no vitamin $D$ winter, the mean $25(\mathrm{OH}) \mathrm{D}$ concentrations were below the deficiency cut-off level of $52 \mathrm{nmol} / \mathrm{L}$ for both males and females $(50.7 \pm 26$ and $46.8 \pm 24 \mathrm{nmol} / \mathrm{L}$, respectively) (40). This was mainly explained by the fact that vitamin D supplementation is seldom used in Greece (either direct or food-related) and by the islanders' darker skin pigmentation which shields them against UVB radiation. We might also speculate that people living in very hot climates may prefer to spend more time indoors than their counterparts living at higher latitudes where summers are generally cooler by comparison (41).

Due to their increasing popularity, a particular mention should be done for vegetarian and vegan diets. Several studies all over the world have shown that vegetarians and vegans are particularly exposed to vitamin D insufficiency and deficiency $(42,43)$. Also lactovegetarians and lactoovovegetarians show lower concentrations of $25(\mathrm{OH}) \mathrm{D}$ compared to non-vegetarians $(44,45)$. Vegetarians and vegans, hence, are recommended to supplement their vitamin D intake. However, since vitamin D3 is derived from animal sources, vegans who, instead, prefer the plant-derived vitamin D2 avoid it. Actually, there are controversies about the equivalence of these two forms of vitamin $D$ (23,46-48).

In contrast to vitamin $\mathrm{D}$ deficiency, toxic concentrations of total $25(\mathrm{OH}) \mathrm{D}$ may cause hypercalcemia (49). Although hypercalcemia does not normally occur at concentrations below $260 \mathrm{nmol} / \mathrm{L}$, we could exploit the high dependence of vitamin $D$ synthesis on UVB radiation to define a safe upper limit based on healthy subjects having maximal UVB exposure. For instance, in native populations living at equatorial latitudes $25(\mathrm{OH}) \mathrm{D}$ concentrations range between $60 \mathrm{nmol} / \mathrm{L}$ and $177 \mathrm{nmol} / \mathrm{L}$ (27). Similarly, healthy subjects not living at the equator but having very high sunlight exposure (like surfers, tanners and outdoor workers) show 25(OH)D concentrations ranging between 73 $\mathrm{nmol} / \mathrm{L}$ and $177 \mathrm{nmol} / \mathrm{L}$. Based on these data, we can assume that $25(\mathrm{OH}) \mathrm{D}$ concentrations of 170 $180 \mathrm{nmol} / \mathrm{L}$ could be considered as a safe range for healthy people who are often exposed to high UVB doses (27).

From a diagnostic point of view, when measuring $25(\mathrm{OH}) \mathrm{D}$ concentration, the circannual rhythm of this metabolite should be considered to avoid repercussions on the diagnosis of vitamin D insufficiency or deficiency. For example, in a patient with summer/autumn values slightly above the minimal threshold suggested by the IOM or the ES, the winter/spring values will probably fall below the desirable range. However, except for the Australian guidelines, the current reference ranges for this metabolite do not include seasonal variation; instead, a single measurement taken at any time of the year is used to extrapolate the patient's vitamin D status throughout the year (29). 


\section{Genetics}

Genome-wide association studies have shown that single nucleotide polymorphisms (SNP) in the vitamin D pathway genes (DHCR7, CYP2R1, CYP3A4, CYP27A1, DBP, LRP2, CUB, CYP27B1, CYP24A1, VDR, and RXRA) influence vitamin D status (50-52). While the vitamin $\mathrm{D}$ concentration is tightly regulated by the expression level of the enzymes involved in its activation and inactivation pathways, such factors account for approximately $5 \%$ of total $25(\mathrm{OH}) \mathrm{D}$ variability $(10,50)$. Consequently, SNPs in the CYP2R1 and DHCR7 genes encoding the enzymes involved in the first steps of $25(\mathrm{OH}) \mathrm{D}$ biosynthesis are of limited importance, yet they have been consistently shown to alter vitamin $D$ status. The most studied SNPs are rs10741657 G>A in the CYP2R1 gene which is associated with higher circulating concentrations of $25(\mathrm{OH}) \mathrm{D}$, and rs12785878 G>T in the DHCR7 gene which is, instead, associated with lower circulating 25(OH)D (50,53-56). In contrast, circulating concentrations of VDBP can sequestrate up to $90 \%$ of total $25(\mathrm{OH}) \mathrm{D}$ (57). Because the bioactive form of vitamin $D$ is its free circulating form, it has been proposed that high levels of VDBP may lower the concentration of free $25(\mathrm{OH}) \mathrm{D}$ and therefore inhibit its physiological role. As expected, mutations in genes encoding VDBP are the most widely investigated, and a number of SNPs have been consistently associated with altered concentrations of vitamin $\mathrm{D}$. Among others, the most extensively studied are the rs4588 and rs7041 genetic polymorphisms which are associated with increased risk of vitamin $D$ deficiency particularly in East Asian population (57,58-62). Variants of VDBP differ markedly between racial groups. For instance, rs1155563 and rs2298849 are associated with lower vitamin D concentrations in African population whereas SNP in the rs17467825, also lowering the concentration of vitamin $D$, are more frequently found in European population respectively $(51,63-65)$. In general, black Americans have lower concentrations of 25(OH)D and VDBP than their white counterparts, despite similar concentrations of bioavailable (free) 25(OH)D (66). The interdependency between VDBP and 25(OH)D concentrations does not seem to have a linear relationship but rather becomes significant at low concentrations of $25(\mathrm{OH}) \mathrm{D}$. For instance, high VDBP concentrations have been correlated with the risk of colorectal cancer (CRC) only in patients with low 25(OH)D concentrations, suggesting that in individuals with normal $25(\mathrm{OH}) \mathrm{D}$ concentrations the VDBP concentration does not significantly influence the bioavailable vitamin $D$ (25). In other words, the higher the VDBP concentrations are, the greater is the amount of bound $25(\mathrm{OH}) \mathrm{D}$; this would lead to reduced concentrations of free and bioavailable $25(\mathrm{OH}) \mathrm{D}$. It follows that the impact of high VDBP concentrations is more pronounced in conditions of low total 25(OH)D.

\section{Age, gender, BMI and ethnicity}

A recent study by Vuistiner et al. reported that gender has little influence on 25(OH)D concentrations (34). Similarly, the effect of age was negligible in adults. A separate discussion, which is beyond the scope of this review, concerns pregnant women in which low $25(\mathrm{OH}) \mathrm{D}$ concentrations are observed worldwide, children, in whom vitamin $D$ deficiency can cause rickets and might be a risk factor for future chronic diseases, and persons with diagnosed illnesses $(27,67)$.

Vuistiner et al. also showed that body-mass index (BMI) is inversely correlated to vitamin D concentrations. This is mostly due to a decrease in time spent in outdoor activities, inadequate diet, and the sequestration of vitamin $D$ by subcutaneous fat (68). As mentioned above, although many of the published studies have been conducted on white people, $25(\mathrm{OH}) \mathrm{D}$ concentrations may differ substantially depending on skin pigmentation. Since the main source of vitamin $D$ is exposure to sunlight, dark skin shields against UVB radiation, increasing the risk for vitamin $D$ deficiency (69). For instance, populations of African origin differ in skin darkness primarily due to the ratio of eumelanin to pheomelanin (70). This difference has genetically evolved because of the different UVB regimes present in their countries of origin and might pose a higher risk of developing vitamin D deficiency in people of African ethnicity living at higher latitudes (71,72). Similarly, genetic variants 
of VDBP can be observed between racial groups (73). These factors should be taken into account when measuring total serum $25(\mathrm{OH}) \mathrm{D}$ in different ethnic groups, particularly in those living at latitudes greatly different than those of their ancestors (27).

\section{Analytical variability}

Precise measurement of vitamin D concentrations is difficult, and large variations exist between different assay methodologies. Such variations depend on several factors: different methods of vitamin D extraction, antibody cross-reactivity with epimers and/or other vitamin D metabolites, and presence of isobaric compounds or matrix interferences $(17,21)$. Table 1 lists the assays most commonly used in clinical laboratories. The assays can be divided in two main categories: 1) assays based on a chromatographic separation step, the most popular of which are liquid chromatography-mass spectrometry (LC/MS) or liquid chromatographytandem mass spectrometry (LC-MS/MS), and 2) non-chromatographic methods based on antibody or protein binding, such as immunoassays. The chromatography-based assays are more consistent and accurate than the antibody-based methods. Since the above mentioned methods are usually based on achiral chromatographic techniques, they cannot distinguish between 25(OH)D3 and its 3-epimer (which concentrations are high in infants but represent only $6 \%$ of total measured 25(OH)D in adults), or other isobaric compounds such as 7-a-hydroxy-4-cholesten-3one (an endogenous precursor of bile acids) result-

TABLE 1. Currently used vitamin D methods

\begin{tabular}{cc}
\hline Method & Proportion, \% \\
\hline Radio immunoassay & 2 \\
Manual immunoassay & 9 \\
Automated immunoassay & 69 \\
LC-MS/MS & 15 \\
Other & 5 \\
\hline
\end{tabular}

LC-MS/MS - liquid chromatography-tandem mass spectrometry. ing in a slight overestimation of vitamin concentrations (74). This problem can be overcome, however, by appropriate (i.e. chiral phase) chromatographic separation (75).

In order to promote laboratory measurement standardization and reduce variability of vitamin D measurement, in 2010 the Office of Dietary Supplements (ODS) of the U.S. National Institutes of Health (NIH) organized the Vitamin D Standardization Programme (VDSP) (76). This Programme also involves the National Institute for Standards and Technology (NIST), the Centers for Disease Control and Prevention (CDC), the Vitamin D External Quality Assessment Scheme (DEQAS), the College of American Pathologists (CAP), the American Association for Clinical Chemistry (AACC), and the International Federation of Clinical Chemistry and Laboratory Medicine (IFCC). The VDSP is now monitoring performance, accrediting laboratories engaged in vitamin D assays, and developing a standard reference measurement procedure (SRMP) system which consists of a set of components and procedure that can be used to calibrate the clinical laboratory instrumentation similarly to the Standard Reference Materials (SRMs) previously produced by the NIST $(24,77)$. On the same line, the CDC provides a vitamin D standardization certification programme and publishes a list of those manufacturers/laboratories that have successfully passed the performance criterion $( \pm 5 \%$ mean bias and overall imprecision of $<10 \%$ over the concentration range of $22-275 \mathrm{nmol} / \mathrm{L}$ for total $25(\mathrm{OH}) \mathrm{D})$. An additional resource to standardize small clinical and research laboratories, as an alternative to the CDC programme, which is expensive and more suited for manufacturers and large laboratories, are the accuracy-based performance testing (PT) programs offered by the CAP and the DEQAS. The latter distributes quarterly five serum samples with $25(\mathrm{OH}) \mathrm{D}$ concentrations previously determined by the NIST to registered laboratories. The laboratories then return their results for quality assessment by the DEQAS (78).

Although much effort has gone in improving accuracy and precision in $25(\mathrm{OH}) \mathrm{D}$ measurements, two recent studies have highlighted substantial within-assay and between-assay variability across 
different commercially available instrumentations $(26,27)$. Both studies compared the results obtained by LC-MS with 5 automated chemiluminescent immunoassays (CLIA) from different manufacturers (Abbott Diagnostics, Diasorin, IDS, Roche Diagnostics, and Siemens) and found that the mass-spectrometry instrumentation has the best performance with a bias $<10 \%$, even at a concentration as low as $5.2 \mathrm{nmol} / \mathrm{L}$. In contrast, most immunoassays had a bias greater than $\pm 15 \%$, and as large as $30 \%$ in some cases. Only the Liaison instrument from Diasorin showed a bias of only $6.4 \%$, which is comparable with that of LC-MS methods. However, the immunoassay biases increased dramatically at low vitamin $D$ concentrations ( $<21 \mathrm{nmol} / \mathrm{L})$ : the bias increased up to $35 \%$ for the Liason, whereas for the other instruments it exceeded $100 \%$ (26).

The large discrepancies between LC-MS methods and immunoassays, but also among different immunoassay methods, is mainly due to the differences in cross-reactivity with various vitamin $D$ metabolites, which accounts for a significant proportion of total $25(\mathrm{OH}) \mathrm{D}(27,79)$. Although immunoassays do not detect 3-epi-25(OH)D3, generating specific antibodies against small antigenic molecules such as $25(\mathrm{OH}) \mathrm{D}$ is challenging, and cross-reactivity with $24,25(\mathrm{OH})_{2} \mathrm{D} 3$ (a product of the vitamin $\mathrm{D}$ catabolic pathway that can be present at concentrations of up to $13 \mathrm{nmol} / \mathrm{L}$ ) and other metabolites of the vitamin $D$ pathway is common $(10,80)$. While some immunoassays cannot detect $25(\mathrm{OH}) \mathrm{D} 2$, those that can are unable to distinguish between 25(OH)D2 and 25(OH)D3, making it difficult to determine abnormalities. Furthermore, the strongly hydrophobic $25(\mathrm{OH}) \mathrm{D}$ is largely bound to VDBPs in blood which compete with the antibody in assays where $25(\mathrm{OH}) \mathrm{D}$ and VDBP are not completely separated; manual extraction can overcome this problem but increases imprecision (26).

The DEQAS noted a substantial improvement in the accuracy and precision of vitamin D measurements after the release of the NIST SRM reference in 2008 (81). Figure 2 shows how the inter-laboratory imprecision has dropped dramatically since then and nicely correlates with the rise in the num-

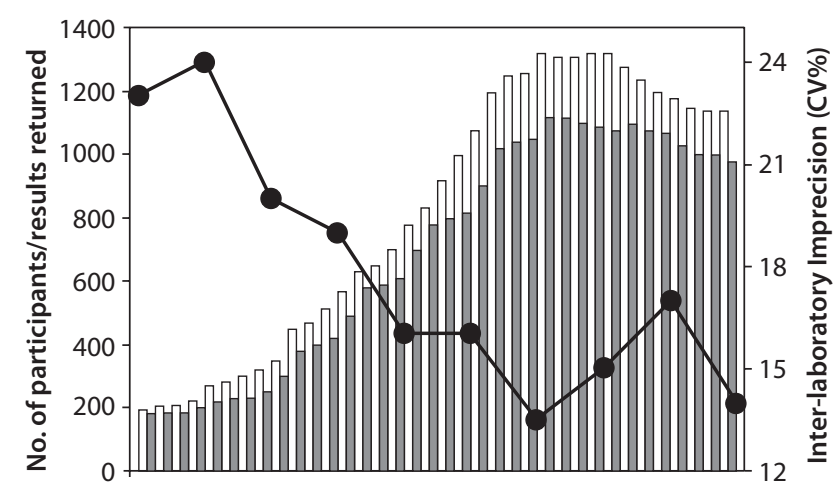

time range: January 2006 - July 2014

Figure 2. Relationship between the mean inter-laboratory imprecision (line and dotted plot) and the number of DEQAS (25-Hydroxyvitamin D measurements) registered laboratories (white bars). Gray bars indicates the numbers of returned results. With permission from DEQAS.

ber of participants in the Assessment Scheme (78). As illustrated in Figure 3, and consistent with the studies by Farrell and Fuleihan discussed above, the mean bias (from the NIST-assigned target values) for a total of 50 samples distributed between 2012 and 2014 has not changed much during this 3-year time period. However, while the LC-MS/MS and HPLC/UV methods have a lower bias (within \pm $15 \%)$, and except for the Diasorin Liaison which has a bias comparable with the LC-MS methods, the other tested immunoassay instruments have biases as high as $\pm 30 \%$ (78). To overcome the problem associated with substantial inter-laboratory variability, the VDSP conducted a retrospective standardization by analysing stored samples available from two national studies: The Third National Health and Nutrition Examination Survey (NHANES III, 1988-1994) and the German Health Interview and Examination Survey for Children and Adolescents (KIGGS, 2003-2006) (82,83). The retrospective standardization showed that the vitamin D values were overestimated in NHANES III and underestimated in KIGGS. When properly applied, the assay standardization proposed by the VDSP can greatly improve the interpretation of research data. Nonetheless, we are still far from having a worldwide vitamin D assay standardization that is capable to provide reliable measurements with a bias within the desirable $\pm 5 \%$ range. Table 

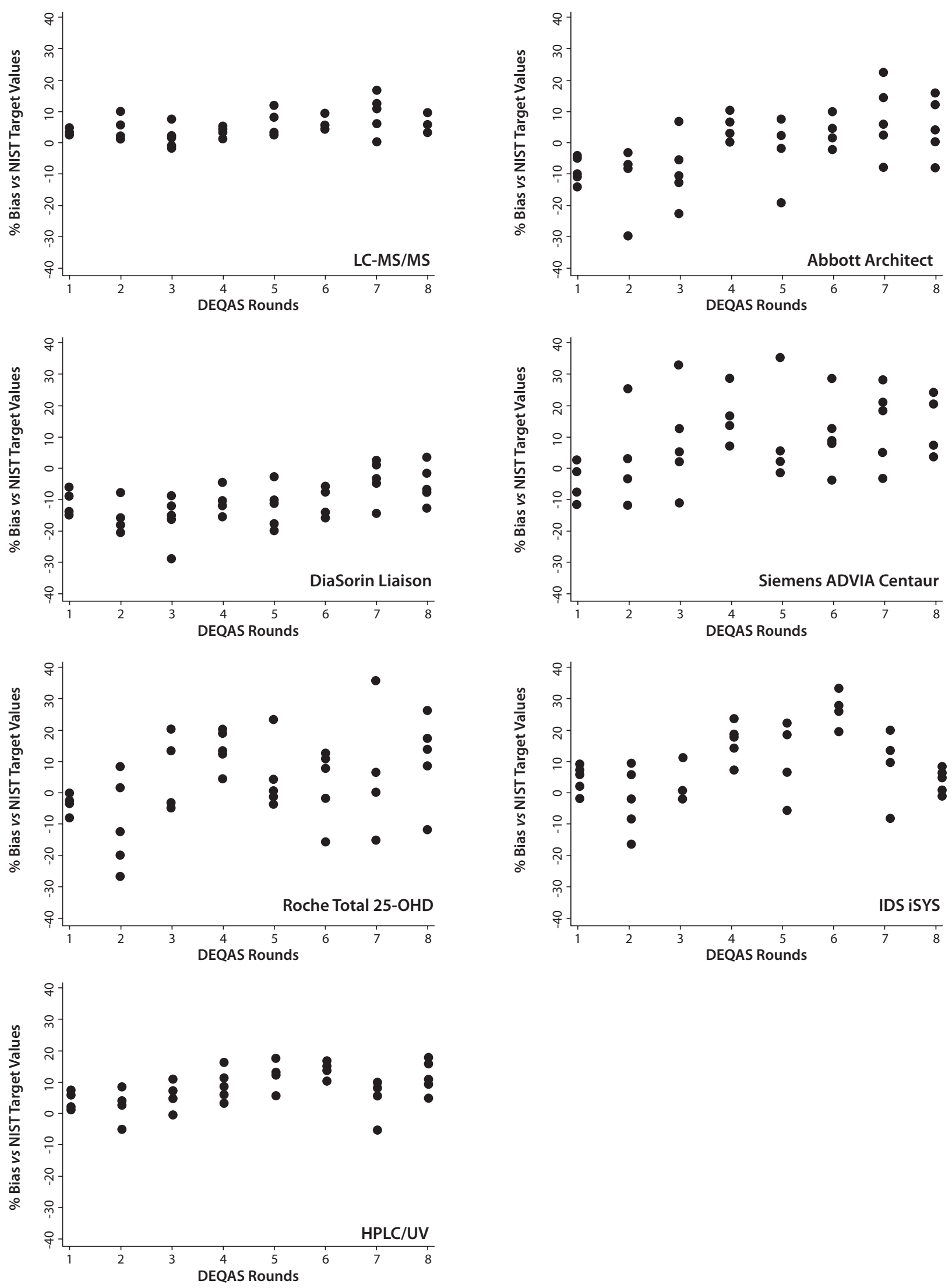

FIGURE 3. Changes in \% bias from the NIST assigned values for each of the major 25(OH)D methods. 40 samples were distributed quarterly (8 rounds, 5 samples at a time) between October 2012 and July 2014 (54). With permission from DEQAS. 
TABLE 2. Advantages and limitations of MS-based methods and immunoassays for vitamin D measurement

\begin{tabular}{|c|c|c|}
\hline Method & Advantages & Limitations \\
\hline MS-based & $\begin{array}{l}\text { - high sample volume (LC-MS) } \\
\text { - availability of reference measurement procedures } \\
\text { - separation of vitamin D metabolites } \\
\text { - allows the inclusion of stable isotope-labelled } \\
\text { standards }\end{array}$ & $\begin{array}{l}\text { - not intended for routine clinical samples analysis } \\
\text { - not fully automated } \\
\text { - complex and expensive instrumentation } \\
\text { - no distinction between epimers }\end{array}$ \\
\hline Immunoassays & $\begin{array}{l}\text { - high sensitivity } \\
\text { - reduced sample volume } \\
\text { - fully automated }\end{array}$ & $\begin{array}{l}\text { - cross-reactivity with other vitamin D metabolites } \\
\text { (e.g., D2 vs. D3) } \\
\text { - measurement of free } 25(\mathrm{OH}) \mathrm{D} \text { requires VDBP } \\
\text { displacement (proprietary methods) }\end{array}$ \\
\hline
\end{tabular}

LC-MS - liquid chromatography-mass spectrometry. VDBP - vitamin D binding proteins.

2 lists the main advantages and limitations of MSbased methods and immunoassays for vitamin $D$ measurement.

\section{Reference ranges}

Measuring 1,25-(OH) 2 in serum is more difficult than measuring its precursor $25(\mathrm{OH}) \mathrm{D}$ due to its peculiar properties: highly lipophilic, highly instable, presence at picomolar concentrations within the circulation, below the detection limits of direct UV or MS methods. Moreover, the immunoassaybased determination of $1,25(\mathrm{OH})_{2} \mathrm{D}$ is affected by the cross-reactivity of antibodies with other vitamin D metabolites thus requiring chromatographic sample pre-purification processes, with extensive manipulation of the sample (84). Serum $25(\mathrm{OH}) \mathrm{D}$ is thus considered the best indicator of the vitamin $D$ status even because, contrarily to $1,25(\mathrm{OH})_{2} \mathrm{D}$, it is not dependent on PTH and directly reflect the entity of the vitamin D stores (18). Current guidelines from scientific bodies recommend the measurement of 25-hydroxy vitamin $D$ $(25(\mathrm{OH}) \mathrm{D})$ in blood as the preferred test, however, because the total serum $25(\mathrm{OH}) \mathrm{D}$ concentration has several subject-specific and environmentaldependent sources of variability, the adoption of a fixed desirable range is inappropriate. The main biological source of variability arises from the tight dependence between UVB exposure and 25(OH)D concentration, resulting in a wide variability of vitamin $D$ concentrations over the course of the year. This should be considered when measuring vitamin $\mathrm{D}$ in individual patients, because summer values slightly above the desirable range of 52 $\mathrm{nmol} / \mathrm{L}$, as suggested by the IOM, will probably fall below such concentrations in the wintertime. Ideally, subject-specific factors related to UVB availability (e.g., outdoor activity, apparel, skin pigmentation, use of sunscreens, living latitude, and winter holidays at low latitudes) should be taken into account to calculate the desirable range. Other factors to be considered are: ethnicity, BMI, and food-related or direct vitamin D supplementation.

Although the short-term biological variability $(6$ weeks) for $25(\mathrm{OH}) \mathrm{D}$ is less than $7 \%$, its concentrations vary, on average, by $40 \mathrm{nmol} / \mathrm{L}$ during the year, with peak changes of up to $105 \mathrm{nmol} / \mathrm{L}$ $(34,85)$. Fohner et al. showed that in healthy subjects living at high latitudes more than $50 \%$ of the biological variability for vitamin $D$ could be explained by relatively few factors (e.g., age, diet, gender, season of sample collection, BMI, latitude, and genotype), while the remaining variability could be ascribed to vitamin $D$ supplementation (86). Similarly, Rees et al. analysed a multivariable model and showed that few factors (sex, baseline serum $25(\mathrm{OH}) \mathrm{D}$, adherence to contraceptive pill intake, apparel, physical activity, use of extra vitamin D-containing supplements, and season of blood collection) accounted for $50 \%$ of vitamin D variability after cholecalciferol supplementation (87). In addition, BMI was associated with baseline serum $25(\mathrm{OH}) \mathrm{D}$ but not with its response to supplemen- 
tal cholecalciferol, and genetic factors did not play a major role, either. Veugelers et al. who proposed three different Recommended Dietary Allowances (RDA) for normal weight, overweight, and obese patients, reported a relationship between $\mathrm{BMI}$ and vitamin D supplementation (88).

In light of these studies, it appears that the desirable range for vitamin $\mathrm{D}$ should be calculated using a validated equation that takes into account the UVB-component, ethnicity, BMI, age, sex, and eventually vitamin D supplementation. Recently, predictive models have been developed that take into account seasonal variability and ethnicity, and seasonal variability and BMI $(34,89)$. In the former study, O'Neil et al. proposed a predictive model (Figure 4) that, by combining the effect of seasonal variability and a component accounting for foodrelated or direct supplement vitamin D fortification, successfully predicted the measured wintertime 25(OH)D concentration for both white and black Asian minority ethnicity (BAME) population groups (89). In another work by Vuistiner et al., the data from more than 7000 people were used to create a population-based model that predicts the centiles of the $25(\mathrm{OH}) \mathrm{D}$ distribution by gender, age, BMI, and taking seasonal variation into account. The model can be used to predict future values of an individual over the course of the year based on a measurement made on a given day. The study involved only white Caucasians to avoid the vitamin $D$ variability caused by differences in ethnical skin pigmentation (34). When the determinants of vitamin D concentrations are different, as for example, two different ethnicities or very different latitudes, the predictive model has to be modified accordingly. Additionally, predictive models can be implemented by including population-pharmacokinetic models, as described by Ocampo-Pelland et al. (90). The available mathematical models seems to be more predictive of vitamin D concentrations in healthy subjects whereas for diseased individuals, or in case of specific physiological conditions (e.g. pregnancy), the adoption of a unique equation might be inappropriate and, in these cases, more frequent measurements of serum 25(OH)D should be the preferred option.

A separate issue concerns instrumental variability which closely depends on the type of assay used. Although the VDSP is making great effort to reduce the within-assay and between-assay variability, the DEQAS review shows that, except for LCMS, the bias for the majority of the currently used instrumentations (see Table 1) is still high and is likely to influence treatment decision making (78).

\section{Conclusions}

The prevalence of vitamin D deficiency and insufficiency is high, and may possibly increase in the future. Therefore, it is desirable to include assess-

$$
\begin{aligned}
& \sqrt{25(O H) D}=\beta_{0}+\beta_{1} \sin \left(\frac{2 \pi(\text { day }-1)}{365}\right) \\
& +\beta_{2} \cos \left(\frac{2 \pi(\text { day }-1)}{365}\right)+\beta_{3} \sin \left(\frac{4 \pi(\text { day }-1)}{365}\right)+\beta_{4} \cos \left(\frac{4 \pi(\text { day }-1)}{365}\right)+\beta_{5} t(B M I) \\
& +\beta_{5} t(\text { BMI })^{2}+\beta_{7} I(\text { male }) I(B M I<25)\left(\mathrm{t}(\text { BMI }-\mathrm{t}(25))^{2}\right. \\
& \left.+\beta_{8} I \text { (female) } \sin \left(\frac{2 \pi(\text { day }-1)}{365}\right)+\beta_{9} I \text { (female }\right) \cos \left(\frac{2 \pi(\text { day }-1)}{365}\right)
\end{aligned}
$$

Figure 4. Predictive model proposed by Vuistiner et al. (34) for 25(OH)D concentrations.

The model was set according to the Bayesian Information Criterion (BIC). Body-mass index (BMI) was transformed using an inverse square-root function $t(x)=-1 / \sqrt{ } x$. Model's coefficients were as follows: $\beta_{0}=-2.754(P=0.295), \beta_{1}=-1.077(P<0.001), \beta_{2}=-0.756(P$ $<0.001), \beta_{3}=0.188(P<0.001), \beta_{4}=0.025(P=0.368), \beta_{5}=-81.08(P=0.002), \beta_{6}=-165.6(P=0.014), \beta_{7}=-1174(P \leq 0.001), \beta_{8}=0.218$ $(P<0.001)$, and $\beta_{9}=0.164(P=0.003)$. The model explained $29 \%$ of the variance. 
ment of vitamin $D$ in routine examination in order to monitor its concentrations and to follow up eventual supplementation regimens. Provided that accurate $25(\mathrm{OH}) \mathrm{D}$ value can be measured, the desirable range should be extrapolated, in individual patients, by an equation considering the time of the year, sun exposure, ethnicity, BMI, the type of assay used and possible intake of vitamin $D$, that can predict the 25(OH)D centile curve for an healthy subject. The discrepancy between the predicted value and the measured $25(\mathrm{OH}) \mathrm{D}$ concentration, at any time of the year, will be then safely used to determine an accurate diagnosis on the patient vitamin $D$ status. If such equations have been developed for otherwise healthy individuals, additional parameters or completely different equations will be needed to assess individual situations like pregnancy, childhood, or diagnosed illnesses.
Although the situation has substantially improved through the efforts of the VDSP, what is still lacking is a general standardization, or at least a harmonization, of methods that provide comparable and, more importantly, less biased results. Ideally, all measurements should be performed using LCMS; however, this scenario being impracticable, we encourage clinical laboratories to adopt an assay traceable to the gold SRMP as proposed by the VDSP in order to calibrate their new and, if available, old measurements $(91,92)$.

\section{Acknowledgements}

This work has been partially funded by the Italian Ministry of Health.

\section{Potential conflict of interest}

None declared.

\section{References}

1. Magno AL, Ward BK, Ratajczak T. The calcium-sensing receptor: A molecular perspective. Endocr Rev 2011;32:3-30. https://doi.org/10.1210/er.2009-0043

2. Anderson PH, Turner AG, Morris HA. Vitamin D actions to regulate calcium and skeletal homeostasis. Clin Biochem 2012;45:880-6. https://doi.org/10.1016/j.clinbiochem.2012.02.020

3. DeLuca HF, Schnoes HK. Metabolism and mechanism of action of vitamin D. Annu Rev Biochem 1976;45:631-66. https://doi.org/10.1146/annurev.bi.45.070176.003215

4. Pike JW, Lee $S M$, Meyer MB. Regulation of gene expression by 1,25-dihydroxy-vitamin D 3 in bone cells : exploiting new approaches and defining new mechanisms. Bonekey Rep 2014;3:482-9. https://doi.org/10.1038/bonekey.2013.216

5. Pike JW, Meyer MB. The vitamin D receptor: new paradigms for the regulation of gene expression by 1,25-dihydroxyvitamin D3. Rheum Dis Clin North Am 2012;38:13-27. https:// doi.org/10.1016/j.rdc.2012.03.004

6. Bouillon $R$, Carmeliet G, Verlinden L, Van Etten E, Verstuyf $A$, Luderer HF, et al. Vitamin D and human health: Lessons from vitamin D receptor null mice. Endocr Rev 2008;29:72676. $h$ ttps://doi.org/10.1210/er.2008-0004

7. Lips P, Van Schoor NM. The effect of vitamin D on bone and osteoporosis. Best Pract Res Clin Endocrinol Metab 2011;25: 585-91. https://doi.org/10.1016/j.beem.2011.05.002
8. Claro da Silva T, Hiller C, Gai Z, Kullak-Ublick GA. Vitamin $D$ transactivates the zinc and manganese transporter SLC30A10 via the Vitamin D receptor. J Steroid Biochem Mol Biol 2016;163:77-87. https://doi.org/10.1016/j. jsbmb.2016.04.006

9. Holick MF, Chen TC, Lu Z, Sauter E. Vitamin D and skin physiology: A D-lightful story. J Bone Miner Res 2007;22(SUPPL. 2):V28-33. https://doi.org/10.1359/jbmr.07s211

10. Prosser DE, Jones G. Enzymes involved in the activation and inactivation of vitamin D. Trends Biochem Sci 2004;29:66473. https://doi.org/10.1016/j.tibs.2004.10.005

11. Fraser DR, Kodicek E. Unique Biosynthesis by Kidney of a Biologically Active Vitamin D Metabolite. Nat Publ 1970;228:361-2. https://doi.org/10.1038/228764a0

12. Penna-Martinez $M$, Badenhoop K. Inherited variation in vitamin $D$ genes Is associated with predisposition to autoimmune disease type 1 diabetes. Diabetes 2011;60:162431. https://doi.org/10.2337/db10-1656

13. Holick MF, Binkley NC, Bischoff-Ferrari HA, Gordon CM, Hanley $D A$, Heaney $R P$, et al. Evaluation, treatment, and prevention of vitamin D deficiency: an Endocrine Society clinical practice guideline. J Clin Endocrinol Metab 2011;96:191130. https://doi.org/10.1210/jc.2011-0385

14. Kiely M, Cashman KD, and on behalf of the ODIN Consortium. The ODIN project: Development of food-based approaches for prevention of vitamin $D$ deficiency throughout life. Nutr Bull 2015;40:235-46. https://doi. org/10.1111/nbu.12159 
15. Webb AR. Who, what, where and when-influences on cutaneous vitamin D synthesis. Prog Biophys Mol Biol 2006;92:1725. https://doi.org/10.1016/j.pbiomolbio.2006.02.004

16. Krzywanski J, Mikulski T, Krysztofiak H, Mlynczak M, Gaczynska E, Ziemba A. Seasonal Vitamin D Status in Polish Elite Athletes in Relation to Sun Exposure and Oral Supplementation. PLoS One 2016;11:e0164395. https://doi. org/10.1371/journal.pone.0164395

17. Lanteri P, Lombardi G, Colombini A, Banfi G. Vitamin $D$ in exercise: Physiologic and analytical concerns. Clin Chim Acta 2013;415:45-53. https://doi.org/10.1016/j. cca.2012.09.004

18. Lombardi G, Colombini A, Freschi M, Tavana R, Banfi G. Seasonal variation of bone turnover markers in top-level female skiers. Eur J Appl Physiol 2011;111:433-40. https://doi. org/10.1007/s00421-010-1664-7

19. Lombardi G, Corsetti R, Lanteri P, Grasso D, Vianello E, Marazzi $M G$, et al. Reciprocal regulation of calcium-/phosphate-regulating hormones in cyclists during the Giro d'Italia 3-week stage race. Scand J Med Sci Sport 2014;24:779-87. https://doi.org/10.1111/sms.12080

20. Halliday TM, Peterson NJ, Thomas JJ, Kleppinger K, Hollis $B W$, Larson-Meyer DE. Vitamin D status relative to diet, lifestyle, injury, and illness in college athletes. Med Sci Sports Exerc 2011;43:335-43. https://doi.org/10.1249/ MSS.0b013e3181eb9d4d

21. Jones $G$. Interpreting vitamin D assay results: Proceed with caution. Clin J Am Soc Nephrol 2015;10:331-4. https://doi. org/10.2215/CJN.05490614

22. Romagnoli E, Mascia ML, Cipriani C, Fassino V, Mazzei F, $D^{\prime}$ Erasmo $E$, et al. Short and long-term variations in serum calciotropic hormones after a single very large dose of ergocalciferol (vitamin D2) or cholecalciferol (vitamin D3) in the elderly. J Clin Endocrinol Metab 2008;93:3015-20. https:// doi.org/10.1210/jc.2008-0350

23. Holick MF, Biancuzzo RM, Chen TC, Klein EK, Young A, Bibuld $D$, et al. Vitamin D2 is as effective as vitamin D3 in maintaining circulating concentrations of 25-hydroxyvitamin D. J Clin Endocrinol Metab 2008;93:677-81. https://doi. org/10.1210/jc.2007-2308

24. Binkley N, Sempos CT. Standardizing vitamin D assays: The way forward. J Bone Miner Res 2014;29:1709-14. https:// doi.org/10.1002/jbmr.2252

25. Ying $H-Q$, Sun $H-L$, He B-S, Pan $Y-Q$, Wang $F$, Deng $Q-W$, et al. Circulating vitamin $D$ binding protein, total, free and bioavailable 25-hydroxyvitamin D and risk of colorectal cancer. Sci Rep 2015;5:7956. https://doi.org/10.1038/srep07956

26. Farrell CJL, Martin S, McWhinney B, Straub I, Williams P, Herrmann $M$. State-of-the-art vitamin D assays: A comparison of automated immunoassays with liquid chromatography-tandem mass spectrometry methods. Clin Chem 2012;58:53142. https://doi.org/10.1373/clinchem.2011.172155

27. Fuleihan GH, Bouillon R, Clarke B, Chakhtoura M, Cooper $C$, McClung $M$, et al. Serum 25-Hydroxyvitamin D levels: variability, knowledge gaps, and the concept of a desirable range. J Bone Miner Res 2015;30:1119-33. https://doi. org/10.1002/jbmr.2536

28. Carter GD. 25-hydroxyvitamin D: A difficult analyte. Clin Chem 2012;58:486-8. https://doi.org/10.1373/ clinchem.2011.180562
29. Nowson CA, McGrath JJ, Ebeling PR, Haikerwal A, Daly RM, Sanders KM, et al. Working Group of Australian and New Zealand Bone and Mineral Society ES of $A$ and OA. Vitamin D and health in adults in Australia and New Zealand: a position statement. Med J Aust 2012;196:686-7. https://doi. org/10.5694/mja11.10301

30. Ross AC, Taylor CL, Yaktine AL, Del Valle HB, eds. Dietary reference intake for calcium and vitamin D. Washington DC: National Academies Press, 2011.

31. Ross AC, Manson JE, Abrams SA, Aloia JF, Brannon PM, Clinton $S K$, et al. The 2011 report on dietary reference intakes for calcium and vitamin D from the Institute of Medicine: what clinicians need to know. J Clin Endocrinol Metab 2011;96:53-8. https://doi.org/10.1210/jc.2010-2704

32. Maxwell JD. Seasonal variation in vitamin D. Proc Nutr Soc 1994;53:533-43. https://doi.org/10.1079/PNS19940063

33. O'Neill CM, Kazantzidis A, Ryan MJ, Barber N, Sempos $C T$, Durazo-Arvizu RA, et al. Seasonal changes in vitamin D-effective UVB availability in Europe and associations with population serum 25-Hydroxyvitamin D. Nutrients 2016;8:533. https://doi.org/10.3390/nu8090533

34. Vuistiner $P$, Rousson V, Henry H, Lescuyer P, Boulat O, Gaspoz J, et al. A population-based model to consider the effect of seasonal variation on serum 25(OH)D and vitamin D status. Biomed Res Int 2015;2015:168189. https://doi. org/10.1155/2015/168189

35. Webb AR, Kline L, Holick MF. Influence of season and latitude on the cutaneous synthesis of vitamin D3: Exposure to winter sunlight in Boston and Edmonton will not promote vitamin D3 synthesis in human skin. J Clin Endocrinol Metab 1988;67:373-8. https://doi.org/10.1210/jcem-67-2-373

36. Lombardi G, Vitale JA, Logoluso S, Logoluso G, Cocco N, Cocco $G$, et al. Circannual rhythm of plasmatic vitamin $D$ levels and the association with markers of psychophysical stress in a cohort of Italian professional soccer players. Chronobiol Int 2017;34:471-9. https://doi.org/10.1080/0742 0528.2017.1297820

37. Brustad M, Alsaker E, Engelsen O, Aksnes L, Lund E. Vitamin $D$ status of middle-aged women at 65-71 degrees $N$ in relation to dietary intake and exposure to ultraviolet radiation. Public Health Nutr 2004;7:327-35. https://doi.org/10.1079/ PHN2003536

38. Lamberg-Allardt C, Brustad M, Meyer HE, Steingrimsdottir L. Vitamin D - a systematic literature review for the 5 th edition of the Nordic Nutrition Recommendations. Food Nutr Res 2013;57:1-31. https://doi.org/10.3402/fnr.v57i0.22671

39. EFSA NDA Panel (EFSA Panel on Dietetic Products, Nutrition and Allergies). Dietary reference values for vitamin D. EFSA Journal 2016;14:4547.

40. Katrinaki M, Kampa M, Margioris A, Castanas E, Malliaraki $N$. Vitamin D levels in a large Mediterranean cohort: Reconsidering normal cut-off values. Hormones 2016;15:205-23. https://doi.org/10.14310/horm.2002.1674

41. King L, Dear K, Harrison SL, van der Mei I, Brodie AM, Kimlin $M G$, et al. Investigating the patterns and determinants of seasonal variation in vitamin D status in Australian adults: the Seasonal D Cohort Study. BMC Public Health 2016;16(892). https://doi.org/10.1186/s12889-016-3582-z

42. Mangels AR. Bone nutrients for vegeterians. Am J Clin Nutr 2014;100:469S-475S. https://doi.org/10.3945/ajcn.113.071423 
43. Craig WJ. Nutrition concerns and health effects of vegetarian diets. Nutr Clin Pract 2010;25:613-20. https://doi. org/10.1177/0884533610385707

44. Outila TA, Kärkkäinen MU, Seppänen RH, Lamberg-Allardt CJ. Dietary intake of vitamin D in premenopausal, healthy vegans was insufficient to maintain concentrations of serum 25-hydroxyvitamin D and intact parathyroid hormone within normal ranges during the winter in Finland. $J$ Am Diet Assoc 2000;100:434-41. https://doi.org/10.1016/ S0002-8223(00)00134-6

45. Crowe FL, Steur M, Allen NE, Appleby PN, Travis RC, Key TJ. Plasma concentrations of 25-hydroxyvitamin $D$ in meat eaters, fish eaters, vegetarians and vegans: results from the EPIC-Oxford study. Public Health Nutr 2011;14:340-6. https://doi.org/10.1017/S1368980010002454

46. Biancuzzo RM, Clarke N, Reitz RE, Travison TG, HolickMF. Serum concentrations of 1,25-dihydroxyvitamin D2 and 1,25-dihydroxyvitamin D3 in response to vitamin D2 and vitamin D3 supplementation. J Clin Endocrinol Metab 2013;98:973-9. https://doi.org/10.1210/jc.2012-2114

47. Logan VF, Gray AR, Peddie MC, Harper MJ, Houghton LA. Long-term vitamin D3 supplementation is more effective than vitamin D2 in maintaining serum 25-hydroxyvitamin D status over the winter months. Br J Nutr 2013;109:1082-8. https://doi.org/10.1017/S0007114512002851

48. Tripkovic L, Lambert H, Hart K, Smith CP, Bucca G, Penson $S$, et al. Comparison of vitamin D2 and vitamin D3 supplementation in raising serum 25-hydroxyvitamin $D$ status: a systematic review and meta-analysis. Am J Clin Nutr 2012;95:1357-64. https://doi.org/10.3945/ajcn.111.031070

49. de Paula FJA, Rosen CJ. Vitamin D safety and requirements. Archiv Biochem Biophys 2012;523:64-72. https://doi. org/10.1016/j.abb.2011.12.002

50. Wang TJ, Zhang F, Richards JB, Kestenbaum B, Van Meurs $J B$, Berry $D$, et al. Common genetic determinants of vitamin D insufficiency: A genome-wide association study. Lancet 2010;376(9736):180-8. https://doi.org/10.1016/S01406736(10)60588-0

51. Ahn J, Yu K, Stolzenberg-Solomon R, Claire Simon K, McCullough ML, Gallicchio L, et al. Genome-wide association study of circulating vitamin D levels. Hum Mol Genet 2010;19:2739-45. https://doi.org/10.1093/hmg/ddq155

52. Jolliffe DA, Walton RT, Griffiths CJ, Martineau AR. Single nucleotide polymorphisms in the vitamin D pathway associating with circulating concentrations of vitamin D metabolites and non-skeletal health outcomes: Review of genetic association studies. J Steroid Biochem Mol Biol 2016;164:1829. https://doi.org/10.1016/j.jsbmb.2015.12.007

53. Ramos-Lopez E, Brück P, Jansen T, Herwig J, Badenhoop K. CYP2R1 (vitamin D 25-hydroxylase) gene is associated with susceptibility to type 1 diabetes and vitamin D levels in Germans. Diabetes Metab Res Rev 2007;23:631-6. https://doi. org/10.1002/dmrr.719

54. Robien K, Butler LM, Wang R, Beckman KB, Walek D, Koh $W-P$, et al. Genetic and environmental predictors of serum 25-hydroxyvitamin D concentrations among middle-aged and elderly Chinese in Singapore. Br J Nutr 2013;109:493502. https://doi.org/10.1017/S0007114512001675
55. Cheung CL, Lau K-SK, Sham P-CP, Tan KC, Kung AW. Genetic variant in vitamin $D$ binding protein is associated with serum 25-hydroxyvitamin D and vitamin D insufficiency in southern Chinese. J Hum Genet 2013;58:749-51. https://doi. org/10.1038/jhg.2013.84

56. Zhang Y, Wang X, Liu Y, Qu H, Qu S, Wang W, et al. The GC, CYP2R1 and DHCR7 genes are associated with vitamin D levels in northeastern Han Chinese children. Swiss Med Wkly 2012;142:w13636. https://doi.org/10.4414/ smw.2012.13636

57. Bikle DD, Gee E, Halloran B, Kowalski MA, Ryzen E, Haddad JG. Assessment of the free fraction of 25-hydroxyvitamin $D$ in serum and its regulation by albumin and the vitamin D-binding protein. J Clin Endocrinol Metab 1986;63:954-9. https://doi.org/10.1210/jcem-63-4-954

58. Lauridsen $A L$, Vestergaard $P$, Hermann AP, Brot C, Heickendorff $L$, Mosekilde $L$, et al. Plasma concentrations of 25-hydroxy-vitamin $D$ and 1,25-dihydroxy-vitamin $D$ are related to the phenotype of Gc (vitamin D-binding protein): A cross-sectional study on 595 - Early postmenopausal women. Calcif Tissue Int 2005;77:15-22. https://doi. org/10.1007/s00223-004-0227-5

59. Wjst $M$, Altmüller J, Braig C, Bahnweg $M$, André E. A genome-wide linkage scan for 25-OH-D3 and 1,25-(OH)2D3 serum levels in asthma families. J Steroid Biochem Mol Biol 2007;103:799-802. https://doi.org/10.1016/j. jsbmb.2006.12.053

60. Abbas S, Linseisen J, Slanger T, Kropp S, Mutschelknauss EJ, Flesch-Janys D, Chang-Claude J. The Gc2 allele of the vitamin $D$ binding protein is associated with a decreased postmenopausal breast cancer risk, independent of the vitamin D status. Cancer Epidemiol Biomarkers Prev 2008;17:133943. https://doi.org/10.1158/1055-9965.EPI-08-0162

61. Sinotte M, Diorio C, Berube S, Pollak M, Brisson J. Genetic polymorphisms of the vitamin $D$ binding protein and plasma concentrations of 25-hydroxyvitamin $D$ in premenopausal women. Am J Clin Nutr 2009;89:634-40. https://doi. org/10.3945/ajcn.2008.26445

62. Fang $Y$, Van Meurs JBJ, Arp P, Van Leeuwen JPT, Hofman A, Pols HAP, et al. Vitamin D binding protein genotype and osteoporosis. Calcif Tissue Int 2009;85:85-93. https://doi. org/10.1007/s00223-009-9251-9

63. Suaini NHA, Koplin JJ, Ellis JA, Peters RL, Ponsonby A-L, Dharmage SC, et al. Environmental and genetic determinants of vitamin D insufficiency in 12-month-old infants. J Steroid Biochem Mol Biol 2014;144:445-54.

64. Elkum N, Alkayal F, Noronha F, Ali MM, Melhem M, Al-Arouj $M$, et al. Vitamin D insufficiency in Arabs and South Asians positively associates with polymorphisms in GC and CYP2R1 genes. PLoS One 2014;9:e113102. https://doi.org/10.1371/ journal.pone.0113102

65. Signorello LB, Shi J, Cai Q, Zheng W, Williams SM, Long J, et al. Common variation in vitamin $D$ pathway genes predicts circulating 25-hydroxyvitamin D levels among African Americans. PLoS One 2011;6:e28623. https://doi.org/10.1371/ journal.pone.0028623

66. Powe $C E$, Evans $M K$, Wenger J, Zonderman $A B$, Berg $A H$, Nalls $M$, et al. Vitamin $D$-Binding Protein and Vitamin $D$ Status of Black Americans and White Americans. N Engl J 
Med 2013;369:1991-2000. https://doi.org/10.1056/NEJMoa1306357

67. Cashman KD. Vitamin D in childhood and adolescence. Postgrad Med J 2007;83:230-5. https://doi.org/10.1136/ pgmj.2006.052787

68. Wortsman J, Matsuoka LY, Chen TC, Lu Z, Holick MF. Decreased bioavailability of vitamin D in obesity. Am J Clin Nutr 2000;72:690-3.

69. Nowson CA, Margerison C. Vitamin D intake and vitamin D status of Australians. Med J Aust 2002;177:149-52.

70. Jablonski NG, Chaplin G. The evolution of skin pigmentation and hair texture in people of African ancestry. Dermatol Clin 2014;32:113-21. https://doi.org/10.1016/j.det.2013.11.003

71. Shieh A, Aloia JF. Assessing Vitamin D Status in African Americans and the Influence of Vitamin D on Skeletal Health $\mathrm{Pa}$ rameters. Endocrinol Metab Clin North Am 2017;46:135-52. https://doi.org/10.1016/j.ecl.2016.09.006

72. Armas LAG, Dowell S, Akhter M, Duthuluru S, Huerter $C$, Hollis $B W$, et al. Ultraviolet- $B$ radiation increases serum 25-hydroxyvitamin D levels: The effect of UVB dose and skin color. J Am Acad Dermatol 2007;57:588-93. https://doi. org/10.1016/j.jaad.2007.03.004

73. Powe CE, Evans MK, Wenger J, Zonderman AB, Berg $A H$, Nalls $M$, et al. Vitamin $D$-binding protein and vitamin $D$ status of black Americans and white Americans. N Engl J Med 2013;369:1991-2000. https://doi.org/10.1056/NEJMoa1306357

74. Shah I, James R, Barker J, Petroczi A, Naughton DP. Misleading measures in Vitamin D analysis: a novel LC-MS/MS assay to account for epimers and isobars. Nutr J 2011;10:46. https://doi.org/10.1186/1475-2891-10-46

75. Hollis BW, Horst RL. The assessment of circulating $25(\mathrm{OH})$ $D$ and 1,25(OH)2D: Where we are and where we are going. J Steroid Biochem Mol Biol 2007;103:473-6. https://doi. org/10.1016/j.jsbmb.2006.11.004

76. Sempos CT, Vesper HW, Phinney KW, Thienpont LM, Coates $P M$, Vitamin D Standardization Program (VDSP). Vitamin $D$ status as an international issue: national surveys and the problem of standardization. Scand J Clin Lab Invest Suppl 2012;243:32-40.

77. Phinney KW, Bedner M, Tai SS, Vamathevan V V, Sander $L C$, Sharpless $K E$, et al. Development and certification of a standard reference material for vitamin $D$ metabolites in human serum. Anal Chem 2012;84:956-62. https://doi. org/10.1021/ac202047n

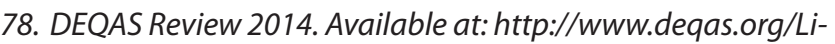
brary.asp?version=101. Accessed May 25th 2017.

79. Lee JH, Choi J-H, Kweon OJ, Park AJ. Discrepancy between Vitamin D Total Immunoassays due to Various Cross-reactivities. J Bone Metab 2015;22:107-12. https://doi. org/10.11005/jbm.2015.22.3.107

80. Coldwell RD, Trafford DJH, Makin HLJ, Varley MJ, Kirk DN. Specific estimation of 24,25-dihydroxyvitamin D in plasma by gas chromatography-mass spectrometry. Clin Chem 1984;30:1193-8.

81. Carter GD, Jones JC. Use of a common standard improves the performance of liquid chromatography-tandem mass spectrometry methods for serum 25-hydroxyvitamin-D. Ann Clin Biochem 2009;46:79-81. https://doi.org/10.1258/ acb.2008.008135
82. Binkley N, Dawson-Hughes B, Durazo-Arvizu R, Thamm M, Tian L, Merkel JM, et al. Title: Vitamin D measurement standardization: The way out of the chaos. J Steroid Biochem Mol Biol 2016 Dec 12 [cited 2017 May 25]. doi: https://doi. org/10.1016/j.jsbmb.2016.12.002. [Epub ahead of print]

83. Cashman KD, Kinsella M, Durazo-Arvizu RA, Tian L, Zhang $Y$, Lucey $A$, et al. Evaluation of Vitamin D Standardization Program protocols for standardizing serum 25-hydroxyvitamin D data: a case study of the program 's potential for national nutrition and health surveys. Am J Clin Nutr 2013;97:1235-42. https://doi.org/10.3945/ajcn.112.057182

84. Hollis BW, Kamerud JQ, Kurkowski A, Beaulieu J, Napoli JL. Quantification of circulating 1,25-dihydroxyvitamin $D$ by radioimmunoassay with 125l-labeled tracer. Clin Chem 1996;42:586-92.

85. Lutsey PL, Parrinello CM, Misialek JR, Hoofnagle AN, Henderson CM, Laha TJ, et al. Short-term Variability of Vitamin D-Related Biomarkers. Clin Chem 2016;62:1647-53. https:// doi.org/10.1373/clinchem.2016.261461

86. Fohner AE, Wang Z, Yracheta J, O'Brien DM, Hopkins SE, Black J, et al. Genetics, diet, and season are associated with serum 25-hydroxycholecalciferol concentration in a Yup'ik Study population from Southwestern Alaska. J Nutr 2016;146:318-25. https://doi.org/10.3945/jn.115.223388

87. Rees JR, Mott L, Barry E, Baron J, Bostick R, Figueiredo J, et al. Lifestyle and Other Factors Explain One-Half of the Variability in the Serum 25-Hydroxyvitamin D Response to Cholecalciferol Supplementation in Healthy Adults. J Nutr 2016;146:2312-24. https://doi.org/10.3945/jn.116.236323

88. Veugelers PJ, Pham T-M, Ekwaru J. Optimal Vitamin D Supplementation Doses that Minimize the Risk for Both Low and High Serum 25-Hydroxyvitamin D Concentrations in the General Population. Nutrients 2015;7:10189-208. https://doi.org/10.3390/nu7125527

89. O'Neill CM, Kazantzidis A, Kiely M, Cox L, Meadows S, Goldberg $G$, et al. A predictive model of serum 25-hydroxyvitamin D in UK white as well as black and Asian minority ethnic population groups for application in food fortification strategy development towards vitamin $D$ deficiency prevention. J Steroid Biochem Mol Biol 2016 Sep 13 [cited 2017 May 25]. doi: https://doi.org/10.1016/j.jsbmb.2016.09.010. [Epub ahead of print]

90. Ocampo-Pelland AS, Gastonguay MR, French JF, Riggs MM. Model-based meta-analysis for development of a population-pharmacokinetic (PPK) model for Vitamin D3 and its 25OHD3 metabolite using both individual and arm-level data. J Pharmacokinet Pharmacodyn 2016;43:191-206. https://doi.org/10.1007/s10928-016-9465-1

91. Tai SS-C, Bedner M, Phinney KW. Development of a candidate reference measurement procedure for the determination of 25-hydroxyvitamin D3 and 25-hydroxyvitamin D2 in human serum using isotope-dilution liquid chromatographytandem mass spectrometry. Anal Chem 2010;82:1942-8. https://doi.org/10.1021/ac9026862

92. Mineva EM, Schleicher RL, Chaudhary-Webb M, Maw KL, Botelho JC, Vesper HW, et al. A candidate reference measurement procedure for quantifying serum concentrations of 25-hydroxyvitamin D and 25-hydroxyvitamin D using isotope-dilution liquid chromatography-tandem mass spectrometry. Anal Bioanal Chem 2015;407:5615-24. https://doi. org/10.1007/s00216-015-8733-z 